INFLAMMATORY BOWEL DISEASE

\title{
Low ileal interleukin 10 concentrations are predictive of endoscopic recurrence in patients with Crohn's disease
}

\author{
B Meresse, P Rutgeerts, H Malchow, S Dubucquoi, J P Dessaint, M Cohard, \\ J F Colombel, P Desreumaux
}

Gut 2002;50:25-28

See end of article for authors' affiliations

Correspondence to: P Desreumaux, Clinique des Maladies de l'Appareil Digestif et de la Nutrition, Hôpital Huriez, CHU Lille, 59037, Lille Cedex,

France;

pdesreumaux@chru-lille.fr

Accepted for publication 10 April 2001

\begin{abstract}
Background: Endoscopic recurrence after surgery in Crohn's disease is frequent and unpredictable. Abnormal intestinal production of pro- (interleukin (IL)-1 $\beta$, tumour necrosis factor $\alpha$ (TNF- $\alpha$ )) and anti(IL-10) inflammatory cytokines has been associated with severe outcome in experimental models of colitis.

Patients and methods: We evaluated if ileal TNF- $\alpha$, IL-1 $\beta$, or IL-10 mRNA levels measured at the time of surgery predict endoscopic recurrence, and if ileal IL-10 levels are associated with particular IL-10 promoter alleles. Ileal biopsies were obtained peroperatively from the healthy neoileum of patients undergoing a right ileocolectomy for Crohn's disease. Mucosal TNF- $\alpha$, IL-1 $\beta$, and IL-10 mRNA levels were quantified by competitive polymerase chain reaction. A cut off value was determined using a receiver operating curve. IL-10.G promoter haplotypes were analysed using a polymorphic dinucleotide repeat in the IL-10 promoter region.

Results: Three months after surgery, $53 \%$ of patients had endoscopic recurrence while $47 \%$ remained free of disease. The risk of endoscopic recurrence correlated with ileal IL-10 mRNA concentrations $\left(r^{2}=0.81\right)$. Endoscopic recurrence occurred more frequently in patients classified as low IL-10 producers than in those that were high producers $(80 \% v 40 \%)(p=0.02)$. Patients with at least one of the two alleles G7-8 or G10-13 produced, respectively, higher $(p=0.006)$ and lower $(p=0.029)$ ileal IL-10 mRNA. The distribution of IL-10.G microsatellite genotypes was similar in patients with or without endoscopic recurrence.

Conclusion: Low ileal IL-10 mRNA concentration is a good marker of endoscopic recurrence in Crohn's disease but the distribution of IL-10.G haplotypes cannot predict the postoperative evolution of the disease.
\end{abstract}

The purpose of this study was to determine if TNF- $\alpha$, IL-1 $\beta$, or IL-10 mRNA concentrations in the ileum at the time of sur-
Abbreviations: $C D$, Crohn's disease; $E R$, endoscopic recurrence; TNF- $\alpha$, tumour necrosis factor $\alpha$; IL, interleukin; TNBS, trinitrobenzene sulphonic acid; PCR, polymerase chain reaction; ROC curve, receiver operating characteristic curve. gery predict ER in CD. As IL-10 production in humans is under genetic control, we also investigated whether intestinal production of IL-10 was associated with particular IL-10 promoter alleles in CD patients.

\section{PATIENTS AND METHODS \\ Patients}

The studies were approved by a local ethics committee and all subjects gave informed consent. The diagnosis of CD was established using standard criteria. ${ }^{8}$

In the first study, ileal TNF- $\alpha$, IL-1 $\beta$, and IL-10 mRNA production was investigated in 36 patients with CD ( 16 males, 20 females; mean age 29 years) who had a first ileocolectomy and ileocolonic anastomosis. All patients underwent surgery because of disease complications-that is, symptomatic stenosis, fistula, obstruction, or disease activity. No patient received immunosuppressive treatment. If patients were being treated with steroids, treatment was tapered and discontinued four weeks before surgery. During the surgical procedure, ileoscopy and biopsy were systematically performed to assess macroscopic and histological integrity, and to quantify cytokine mRNA production in the ileal mucosa $30 \mathrm{~cm}$ above the anastomosis. Eight biopsies were taken from macroscopically non-inflamed ileal mucosa. Some specimens were fixed 
Table 1 Description of the criteria of Rutgeerts et al for endoscopic recurrence 9

\begin{tabular}{ll}
\hline Score & Lesions \\
\hline i0 & No lesions \\
i1 & $<5$ aphthous lesions \\
i2 & $>5$ aphthous lesions with normal mucosa between \\
& the lesions, or skip areas of larger lesions, or lesions \\
& confined to the ileocolonic anastomosis (that is, $<1$ \\
& cm in length) \\
i3 & Diffuse aphthous ileitis with diffusely inflamed \\
& mucosa \\
i4 & noffuse inflammation with already larger ulcers, \\
&
\end{tabular}

in formalin and examined and the rest were immediately frozen in liquid nitrogen. No medical treatment (that is, steroids, salicylates, antibiotics, immunosuppressive drugs) except for antidiarrhoeal and antispasmodic drugs was allowed for a period of three months after surgery. Recurrence was evaluated by endoscopy at three months and scored il-i4 according to the criteria of Rutgeerts et al (table 1). ${ }^{9}$

In the second study, ileal IL-10 mRNA production and IL-10 promoter haplotypes were determined in 43 additional patients with CD ( 18 males, 25 females; mean age 31 years). Biopsies from non-inflamed ileal mucosa were obtained at endoscopy. DNA was extracted from blood samples of all patients in the two studies $(\mathrm{n}=79,34$ males, 45 females; mean age 30 years) to study microsatellite $\mathrm{G}$ allele frequencies of the IL-10 promoter.

\section{Ileal cytokine mRNA quantification by reverse transcription-competitive polymerase chain reaction}

Biopsies were homogenised by mechanical dispersion in Trizol (Bioprobe, Montreuil, France) and total RNA was extracted as previously described. ${ }^{10}$ After treatment at $37^{\circ} \mathrm{C}$ for 30 minutes with 20-50 units of DNase I RNase-free (Boehringer, Mannheim, Germany), total RNA was reverse transcribed into complementary DNA (cDNA) using Moloney murine leukaemia virus reverse transcriptase (Gibco-BRL, Cergy Pontoise, France), $5 \mu \mathrm{M}$ oligo-dT16, and $2.5 \mathrm{mM}$ of each of the four dNTP (Pharmacia, Orsay, France) in a final reaction volume of $20 \mu \mathrm{l}$ in the presence of $1 \mathrm{U} / \mu \mathrm{l}$ of human placenta ribonuclease inhibitor (Promega, Lyon, France). Samples were incubated at $42^{\circ} \mathrm{C}$ for 60 minutes followed by heating for five minutes at $95^{\circ} \mathrm{C}$ and stored at $-20^{\circ} \mathrm{C}$ until use. Competitive polymerase chain reaction (PCR) analysis was performed as described by Zou and colleagues ${ }^{11}$ with some modifications. cDNA (l $\left.\mu \mathrm{l}\right)$ was subjected to PCR using primers specific for $\beta$-actin (5'-GGGTCAGAAGGATTCCTATG-3'; 5'-GGTCTCAAACATGA TCTGGG-3'), IL-10 (5'-AAATTTGGTTCTAGGCCGGG-3'; 5'GAGTACAGGGGCATGATATC- $\left.3^{\prime}\right)$, TNF- $\alpha$ (5'-ACAAGCCTGT AGCCCATGTT-3'; $5^{\prime}$-AAAGTAGACCTGCCCAGACT-3'), and IL- $1 \beta$ (5'-GGATATGGAGCAACAAGTGG-3'; 5'-ATGTACCA GTTGGGGAACTG-3'). The $20 \mu \mathrm{l}$ reaction mixture consisted of sense and antisense primers $(0.1 \mu \mathrm{g} / \mu \mathrm{l}$ each $), 1 \mathrm{U}$ of Taq polymerase (Perkin Elmer, Courtaboeuf, France), $50 \mu \mathrm{M}$ of each of the four dNTP, $1 \times$ PCR buffer (Perkin Elmer) supplemented with $2.5 \mathrm{mM} \mathrm{MgCl}_{2}$, and grade concentrations of one of the two competitors pQAl and pQB2. Amplification was performed by 40 cycles, consisting of denaturation at $94^{\circ} \mathrm{C}$ for one minute, primer annealing for one minute at $55^{\circ} \mathrm{C}$ for IL- 10 and $\beta$-actin or $58^{\circ} \mathrm{C}$ for IL- $1 \beta$ and TNF- $\alpha$, and primer extension at $72^{\circ} \mathrm{C}$ for 1.5 minutes using a GeneAmp PCR system 9700 (Perkin Elmer). After amplification, separation of the DNA competitor and target cDNA was achieved by electrophoresis in 3\% agarose containing ethidium bromide for one hour at $100 \mathrm{~V}$. The amount of PCR products generated by competitor and target cDNA was compared using an image
Table 2 Demography and disease history in the 36 patients with (ER+) or without (ER-) postoperative endoscopic recurrence (ER) of Crohn's disease (CD)

\begin{tabular}{lcc}
\hline & ER- & ER+ \\
\hline Age (yr) & 30 & 28 \\
Sex ratio (F/M) & $10 / 7$ & $10 / 9$ \\
Smoking history (\%) & 50 & 67 \\
CD duration before resection (y) & 5.6 & 4 \\
Disease location & & \\
Ileum & $64 \%$ & $44 \%$ \\
Colon & $0 \%$ & $0 \%$ \\
$\quad$ lleum and colon & $36 \%$ & $56 \%$ \\
Reason for resection & & \\
Fibrostenosis & $64 \%$ & $50 \%$ \\
Obstruction & $14 \%$ & $0 \%$ \\
Fistula/abscess & $14 \%$ & $30 \%$ \\
Disease activity & $7 \%$ & $20 \%$ \\
\hline & & \\
\end{tabular}

analyser (Bioprofil, Marne-la-Vallée, France). Results of cytokine measurements were expressed in proportion to the number of $\beta$-actin cDNA in the same sample.

\section{IL-10.G microsatellite genotyping}

DNA extraction was performed using a Wizard kit (Promega). Genotyping at the IL-10.G microsatellite was carried out using the following primer sequences labelled with 6-carboxyfluorescein (6-FAM 5'-GTCCTTCCCCAGGTAGAGC AACACTCC-3'; 5'-CTCCCAAAGAAGCCTTAGTAGTGTTG-3') with the previously described final reaction mix. After an initial melting time of seven minutes at $95^{\circ} \mathrm{C}$, samples were subjected to 30 rounds of $94^{\circ} \mathrm{C}$ for one minute, $65^{\circ} \mathrm{C}$ for one minute, $72^{\circ} \mathrm{C}$ for one minute, with a final extension time of five minutes at $72^{\circ} \mathrm{C}$ in a GeneAmp PCR sytem 9700. A sample ( $1 \mu \mathrm{l}$ ) of the PCR products was mixed with formamide, loading buffer E, and $0.5 \mu \mathrm{l}$ of ROX-500 standard size (PE Applied Biosystems), heated to $95^{\circ} \mathrm{C}$ for five minutes and then cooled immediately on ice. Fragment sizes were analysed on a sequencing gel containing $6 \%$ acrylamide and $6 \mathrm{M}$ urea with a 377XL DNA sequencer (Perkin Elmer).

\section{Statistical methods}

Correlation between ileal IL-10 mRNA concentrations and the risk of ER was tested using the Pearson's test. To classify patients as low or high IL-10 producers, an IL-10 mRNA cut off value was determined using a receiver operating characteristic (ROC) curve. The risk of recurrence for low and high producers was compared using the $\chi^{2}$ test.

To evaluate IL-10 mRNA production for each allele, we compared IL-10 mRNA concentrations in patients having the allele with all others, using a Kruskall-Wallis one way ANOVA test.

\section{RESULTS}

Prognostic value of ileal TNF- $\alpha$, IL- $1 \beta$, and IL-10 mRNA levels in CD recurrence

Nineteen of the 36 patients had ER greater than il (53\%) and $17(47 \%)$ had no signs of ER. Age, sex, smoking habit, disease duration, disease location, and indications for surgery did not differ between these two groups (table 2). Despite high tissue concentrations of $\beta$-actin mRNA (14 591 (69 587) molecules) in all biopsy specimens, TNF- $\alpha$ and IL-1 $\beta$ mRNA were only detectable in $2 / 36$ and $5 / 36$ samples, respectively. No relation was found between ileal TNF- $\alpha$ and IL-1 $\beta$ mRNA expression at surgery and the risk of recurrence three months later.

In contrast, IL-10 mRNA expression was found in all biopsies from the 36 patients (mean $5.4 \times 10^{4}$ molecules/molecule of $\beta$-actin), with a large variation in concentrations, ranging from $10^{-2}$ to $1.3 \times 10^{6}$ molecules/molecule of $\beta$-actin (fig 1A). 

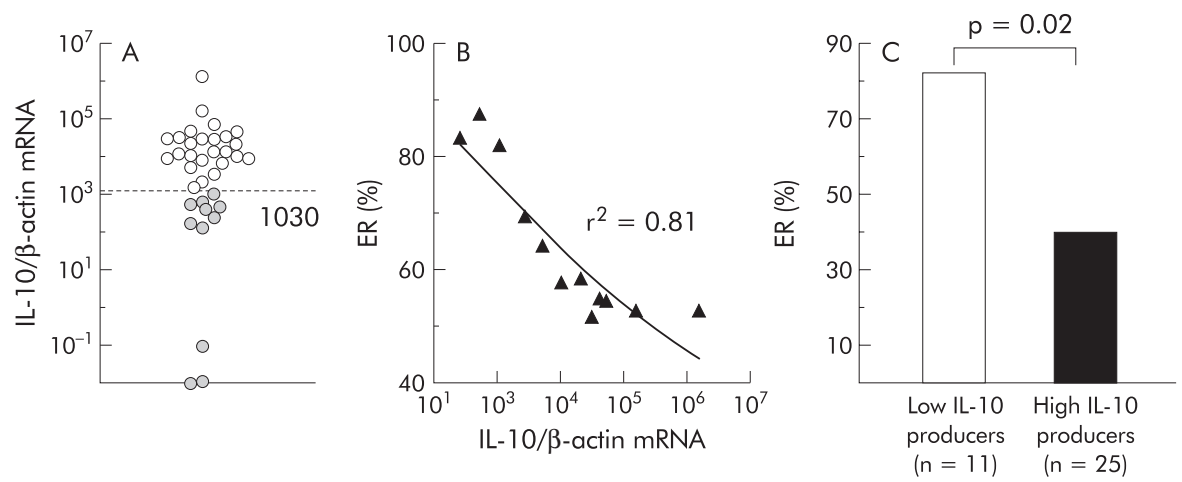

Figure 1 (A) Ileal interleukin (IL)-10 mRNA molecules per $\beta$-actin molecule in the macroscopically non-inflamed ileal mucosa from 36 patients operated on for Crohn's disease. (B) Correlation between ileal IL-10 mRNA and the risk of endoscopic recurrence (ER). (C) Higher frequency of ER in the group of low IL-10 producers than in the group of high IL-10 producers, as defined by a cut off value of 1030 IL-10 mRNA molecules/molecule of $\beta$-actin (broken line in (A)).
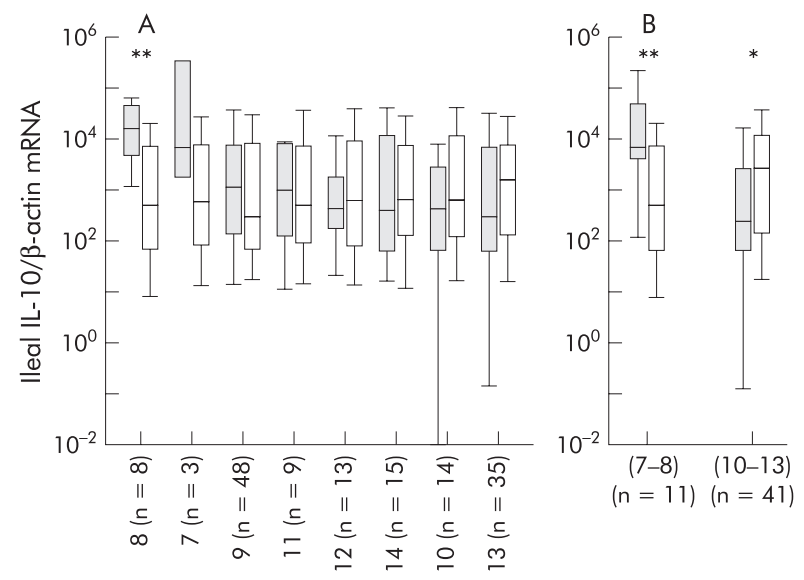

IL-10 G alleles

Figure 2 (A) Median values (horizontal bars in box) of ileal interleukin (IL)-10 mRNA in the 79 patients according to their different IL-10.G alleles, plotted in decreasing values of ileal IL-10 mRNA. Differences in IL-10 synthesis in patients with a least one copy of the allele (shaded box) compared with all other patients (open box) was significant only for the G8 allele (** $p<0.001$ ). (B) Compared with an average of all other alleles combined (open box), concentrations of ileal IL-10 mRNA were significantly different in patients with at least one of G7-8 (** $p<0.001$ ) or G10-13 alleles (shaded box) ( $\left.{ }^{*} p<0.05\right)$.

IL-10 mRNA concentrations correlated with the risk of ER $\left(r^{2}=0.81\right)$ (fig 1B). Using an IL-10 mRNA cut off value of 1030 (as determined using an ROC curve), 11 (31\%) patients were classified as low IL-10 producers and $25(69 \%)$ as high producers (fig lA). ER occurred in $82 \%$ (9/11) of the low producers compared with $40 \%(10 / 25)$ in the high producers $(p=0.02)$ (fig lC). Low ileal IL-10 mRNA concentrations had $88 \%$ specificity and $82 \%$ positive predictive value for ER. TNF- $\alpha$ and IL- $1 \beta$ mRNA were detected with a similar frequency in low (respectively one and two patients) and high (respectively one and three patients) IL-10 producers.

\section{Correlation of IL-10.G microsatellite genotypes with spontaneous IL-10 mRNA production and postoperative endoscopic recurrence}

To investigate the possible association between IL-10.G alleles and the ileal concentration of IL-10 mRNA, we quantified IL-10 mRNA in the uninflamed ileum of 43 additional patients with CD. Considering these patients together with the 36 patients included in the first study, levels of ileal IL-10 mRNA in the 79 patients varied with their IL-10.G alleles. As shown in figure 2, 14\% of patients with the G7 or G8 alleles had the
Table 3 Interleukin (IL)-10.G microsatellite allele frequencies according to endoscopic recurrence (ER) after surgery in the 36 patients with Crohn's disease

\begin{tabular}{lccc}
\hline IL-10.G alleles & ER- $(\%(\mathrm{n}))$ & ER+ (\% (n)) & $\begin{array}{l}\text { Total allele } \\
\text { frequencies } \\
(\mathrm{n}=72)\end{array}$ \\
\hline IL-10.G7-8 & $2.9 \%(1)$ & $7.9 \%(3)$ & $5.5 \%$ \\
IL-10.G10-13 & $26.5 \%(9)$ & $10.5 \%(4)$ & $18 \%$
\end{tabular}

ER-, no endoscopic recurrence; ER+, endoscopic recurrence defined as a Rutgeerts score $\geqslant 1$.

highest ileal IL-10 mRNA production whereas the 57\% of patients with the G10 or G13 alleles had the lowest IL-10 mRNA production. Differences in IL-10 mRNA synthesis in patients having one allele compared with those with all other alleles was significant only for the G8 allele (16 $888 v 504$; $\mathrm{p}=0.0098$ ) (fig 2A). However, compared with an average of all other alleles combined, concentrations of ileal IL-10 mRNA were significantly different in patients with at least one of the two G7-8 (median $6893 v 504 ; \mathrm{p}=0.006$ ) or G10-13 (median $249 \vee 2711 ; p=0.029$ ) alleles (fig $2 B$ ). The frequencies of the G7-8 and G10-13 alleles were similar in the 36 patients with or without recurrence (table 3 ).

\section{DISCUSSION}

Many attempts have been made to identify predictors of recurrence after resection for CD. Patient and disease related factors such as smoking habit, ${ }^{12}$ site of intestinal involvement, and form of disease ${ }^{13}$ have been indicated. In our study, age, sex, smoking habit, disease duration and location, and indications for surgery were not predictive of recurrence. However, ileal IL-10 mRNA concentrations quantified by competitive PCR reflected an increased risk of relapse. These results suggest for the first time that determination of ileal IL-10 mRNA concentrations at the time of surgery may define patients at higher risk of relapse requiring more intensive aftercare.

In contrast with the study of Schreiber et al showing that increased secretion of TNF- $\alpha$ and IL-1 $\beta$ may predict clinical relapse in patients in steroid induced remission, ${ }^{4} \mathrm{TNF}-\alpha$ and IL-1 $\beta$ mRNA levels were not predictive of postoperative recurrence in our study. This discrepancy may be explained at least in part by the definition of recurrence (endoscopic $v$ clinical) and the different disease phases of the patients studied. We have previously shown that different cellular and molecular mediators are involved in the early lesions occurring in the neoileum $^{3}$ and in the established lesions seen in patients after 
steroid induced remission. ${ }^{4}$ The fact that different mediators are predictive of early intestinal recurrence after surgery or of clinical relapses in patients with established lesions suggests that different mechanisms are involved in these two different phases of the disease. Another explanation may be that methods used to quantify cytokines were different. Schreiber et al investigated the capacity of isolated lamina propria mononuclear cells to produce TNF- $\alpha$ and IL- $1 \beta$ by ELISA after in vitro stimulation whereas we quantified mRNA of these cytokines in vivo, directly on unstimulated biopsies taken from the healthy ileal mucosa. Under such circumstances TNF- $\alpha$ and IL- $1 \beta$ may be undetectable. As IL-10 downregulates TNF- $\alpha$ and IL- $1 \beta$ secretion, ${ }^{14}$ it would be interesting to determine whether stimulated lamina propria mononuclear cells produce more proinflammatory cytokines in the low IL-10 producer group than in the high IL-10 producer group.

Many factors are involved in the control of IL-10 production. Analyses of differences in spontaneous IL-10 production in monozygotic and dizygotic twins and non-related individuals suggest that the capacity for IL-10 production has a major genetic component. ${ }^{15}$ Striking differences among individuals in their ability to produce IL-10 (by lipopolysaccharide activated whole blood culture) are the result of differing rates of IL-10 mRNA synthesis which has been ascribed to polymorphisms in the IL-10 gene promoter. Sixteen alleles in a highly polymorphic microsatellite marker, namely IL-10.G within the IL-10 promoter, have been described. ${ }^{16}$ Studies related to IL-10 promoter structures in humans have shown that after in vitro stimulation of peripheral blood leucocytes, haplotypes containing the G7 and G14 alleles were respectively associated with lower or higher IL-10 production. ${ }^{17}$ The question of whether IL-10 promoter structures are associated with spontaneous in vivo production of intestinal IL-10 mRNA remains to be addressed. In the present study, the G14 allele was not significantly associated with higher intestinal IL-10 production. However, we found that G7-8 alleles were associated with the greatest increase in ileal IL-10 mRNA production whereas the G10-13 alleles had the lowest levels. These results suggest that the capacity for intestinal IL-10 production is controlled at least in part by genetic components, which are partially different from those associated with IL-10 production by activated peripheral blood cells. Because IL-10 gene promoter polymorphisms are not correlated with recurrence, we believe that they are not practical genetic markers to predict postoperative ER. The discrepancy between the rate of IL-10 mRNA production and the IL-10 gene promoter polymorphisms in relation to ER may be explained at least in part by the involvement of other genetic influences or environmental factors such as alimentation, ${ }^{18}{ }^{19}$ infection, ${ }^{20}$ or bacterial flora ${ }^{21}$ which may also influence intestinal IL-10 production.

\section{ACKNOWLEDGEMENTS}

This study was supported by a grant from the Conseil Regional du Nord Pas de Calais and CHU de Lille to B Meresse. The authors would like to thank the IFR 22, C Bisiaux (EPI 0114, CHU Lille, France), C Mouton, and M Crépin (plateau technique de séquencage, CHU Lille, France) for technical assistance.

\section{Authors' affiliations}

B Meresse, Equipe Propre Institut National de la Santé et de la Recherche Médical 0114 sur la Physiopathologie des Maladies Inflammatoires Intestinales, CHU Lille, France, and Service d'Immunologie EA 2686, CHU Lille, France

J F Colombel, P Desreumaux, Equipe Propre Institut National de la Santé et de la Recherche Médical 0114 sur la Physiopathologie des Maladies Inflammatoires Intestinales, CHU Lille, France

S Dubucquoi, J P Dessaint, Service d'Immunologie EA 2686, CHU Lille, France

P Rutgeerts, Department of Medicine, University of Leuven, Leuven, Belgium

H Malchow, Klinikum Leverkusen, Leverkusen, Germany

M Cohard, Schering-Plough Research, Institute, Kenilworth, NJ, USA

\section{REFERENCES}

1 Rutgeerts PJ. Postoperative recurrence prophylaxis in Crohn's disease: an update. Res Clin Forums 1998:20:49-55

2 Rutgeerts P, Geboes K, Vantrappen G, et al. Predictability of the postoperative course of Crohn's disease. Gastroenterology 1990;99:956-63

3 Desreumaux P, Brandt E, Gambiez L, et al. Distinct cytokine patterns in early and chronic ileal lesions of Crohn's disease. Gastroenterology 1997;113:118-26.

4 Schreiber S, Nikolaus S, Hampe J, et al. Tumour necrosis factor alpha and interleukin 1 beta in relapse of Crohn's disease. Lancet 1999:353:459-61.

5 Kühn R, Löhler J, Rennick D, et al. Interleukin-10-deficient mice develop chronic enterocolitis. Cell 1993;75:263-74.

6 Barbara G, Xing Z, Hogaboam CM, et al. Interleukin 10 gene transfer prevents experimental colitis in rats. Gut 2000;46:344-9.

7 Duchmann R, Schmitt E, Knolle $P$, et al. Tolerance towards resident intestinal flora in mice is abrogated in experimental colitis and restored by treatment with interleukin-10 or antibodies to interleukin-12. Eur J Immunol 1996;26:934-8

8 Gower-Rousseau C, Salomez JL, Dupas JL, et al. Incidence of inflammatory bowel disease in northern France (1988-1990). Gut 1994:35:1433-8.

9 Rutgeerts P, Geboes K, Vantrappen G, et al. Predictability of the postoperative course of Crohn's disease. Gastroenterology 1990;99:956-63.

10 Estaquier J, Idziorek T, Zou W, et al. T helper type 1/T helper type 2 cytokines and T cell death: preventive effect of interleukin 12 on activation-induced and CD95 (FAS/APO-1)-mediated apoptosis of CD4+ $T$ cells from human immunodeficiency virus-infected persons. J Exp Med 1995:182:1759-67.

11 Zou W, Durand-Gasselin I, Dulioust A, et al. Quantification of cytokine gene expression by competitive PCR using a colorimetric assay. Eur Cytokine Netw 1995;6:257-64

12 Yamamoto T, Keighley MR. Smoking and disease recurrence after operation for Crohn's disease. Br J Surg 2000;87:398-404.

13 Williams JG, Wong WD, Rothenberger DA, et al. Recurrence of Crohn's disease after resection. Br J Surg 1991;78:10-19.

14 Moore KW, O'Garra A, de Waal Malefyt R, et al. Interleukin-10. Annu Rev Immunol 1993;11:165-90

15 Westendorp RG, Langermans JA, Huizinga TW, et al. Genetic influence on cytokine production and fatal meningococcal disease. Lancet 1997;349:170-3.

16 Eskdale J, Kube D, Gallagher G. A second polymorphic dinucleotide repeat in the $5^{\prime}$ flanking region of the human IL 10 gene. Immunogenetics 1996:45:82-3.

17 Eskdale J, Gallagher G, Verweij CL, et al. Interleukin 10 secretion in relation to human IL-10 locus haplotypes. Proc Natl Acad Sci USA 1998;95:9465-70

18 Sudo N, Aiba Y, Takaki A, et al. Dietary nucleic acids promote a shift in Th1/Th2 balance toward Th1-dominant immunity. Clin Exp Allergy 2000;30:979-87.

19 Kleemann R, Scott FW, Worz-Pagenstert U, et al. Impact of dietary fat on Th1/Th2 cytokine gene expression in the pancreas and gut of diabetes-prone BB rats. J Autoimmun 1998;11:97-103.

20 Huang DS, Lopez MC, Wang JY, et al. Alterations of the mucosal immune system due to Cryptosporidium parvum infection in normal mice. Cell Immunol 1996;173:176-82.

21 Chen T, Isomaki P, Rimpilainen $M$, et al. Human cytokine responses induced by gram-positive cell walls of normal intestinal microbiota. Clin Exp Immunol 1999;1 18:261-7. 